\title{
Advancement flap technique for a rare complex anal fistula with synovial cyst at the ischial tuberosity
}

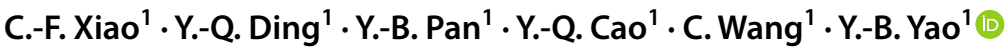

Received: 30 December 2021 / Accepted: 17 January 2022 / Published online: 2 March 2022

(c) The Author(s) 2022

Complex anal fistula with synovial cyst at the ischial tuberosity is a very rare condition. The key point in the operation is to protect the anal sphincter and completely peel off the cyst. Here, we report a successful case of closing the internal opening with the advancement flap technique and completely stripping the cyst (Figs. 1, 2, 3, 4, 5).
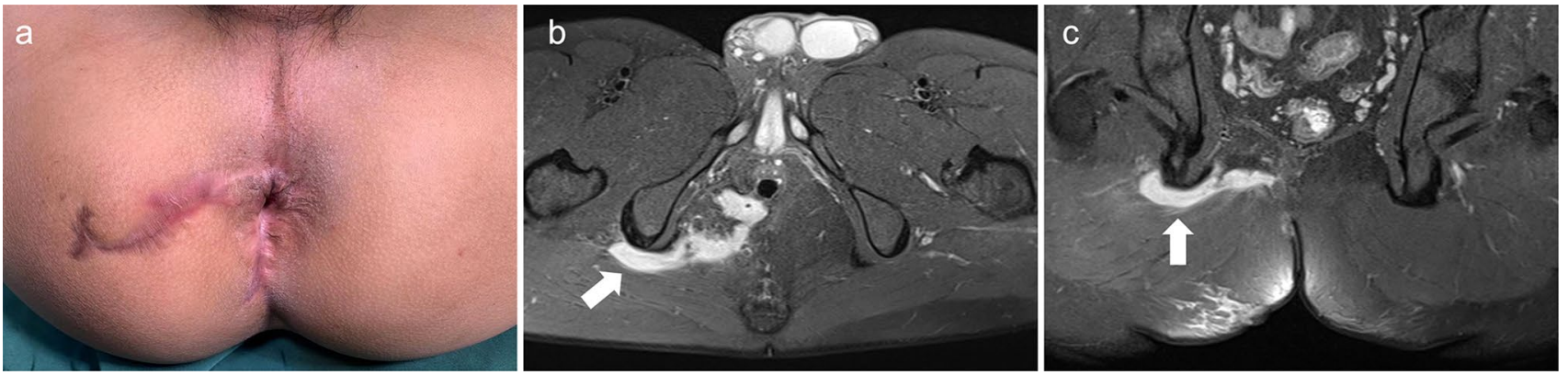

Fig. 1 A 28-year-old man with a history of three operations for complex anal fistula presented to our department complaining of perianal discomfort. a Physical examination revealed 2 old surgical scars around the anus. b-c Perianal magnetic resonance imaging (MRI) was used for preoperative diagnosis and showed that the fistula passed through the anal sphincter to the outer lower edge of the right ischial tuberosity (white arrow)

Chang-Fang Xiao and Ya-Qing Ding contributed equally to this work and are co-first authors.

\footnotetext{
C. Wang

wangchen_longhua@163.com

Y.-B. Yao

elevenzoe@163.com

1 Department of Anorectal Surgery, Longhua Hospital, Shanghai University of Traditional Chinese Medicine, Shanghai, China
} 
Fig. 2 An internal opening was found above the dentate line at 7 o'clock in the lithotomy position. a Two surgical scars were cut during the operation, and cystic wall like tissue (white arrow) was found at the ischial tuberosity, which was consistent with the MRI findings. Based on MRI and intraoperative findings synovial cysts of the ischial tuberosity were suspected, and postoperative pathology findings supported this diagnosis. b-d The advancement flap was freed to cover the internal opening without tension, after the lesion was completely removed and the gluteus maximus was reconstructed
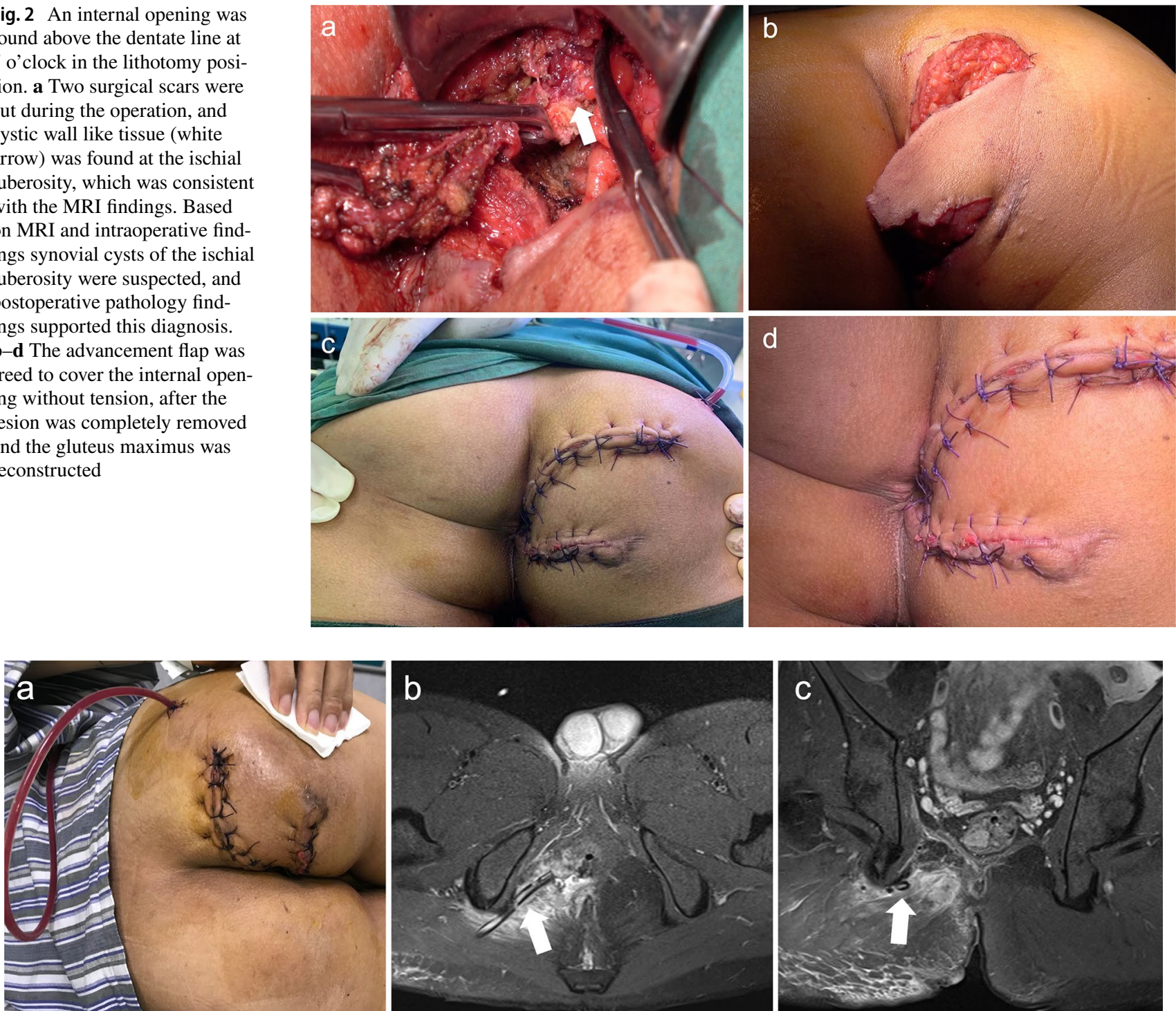

Fig. 3 After reexamination of MRI on postoperative day 8, it was found that there was no obvious effusion, and then the drainage tube was removed. b-c MRI on postoperative day 8 (white arrow: drainage tube)

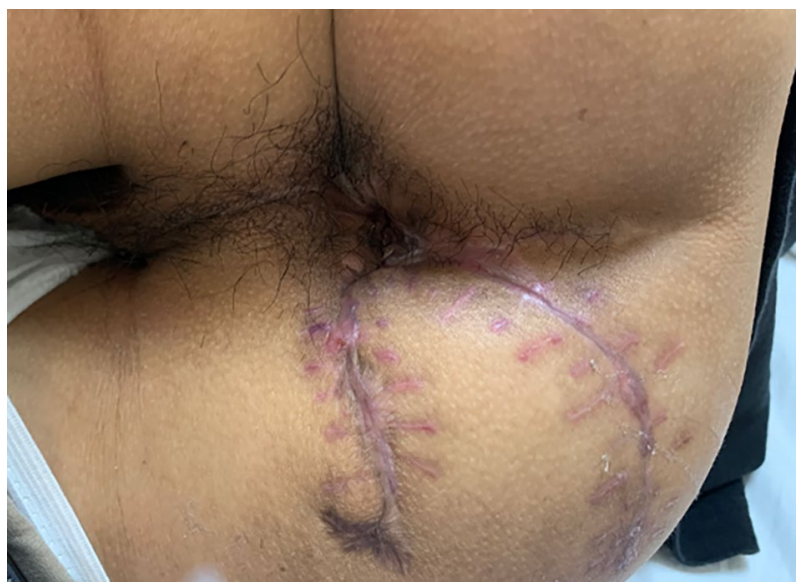

Fig. 4 Wound healing 2 months after the operation 
Fig. 5 MRI 5 months after the operation. Imaging showed excellent healing
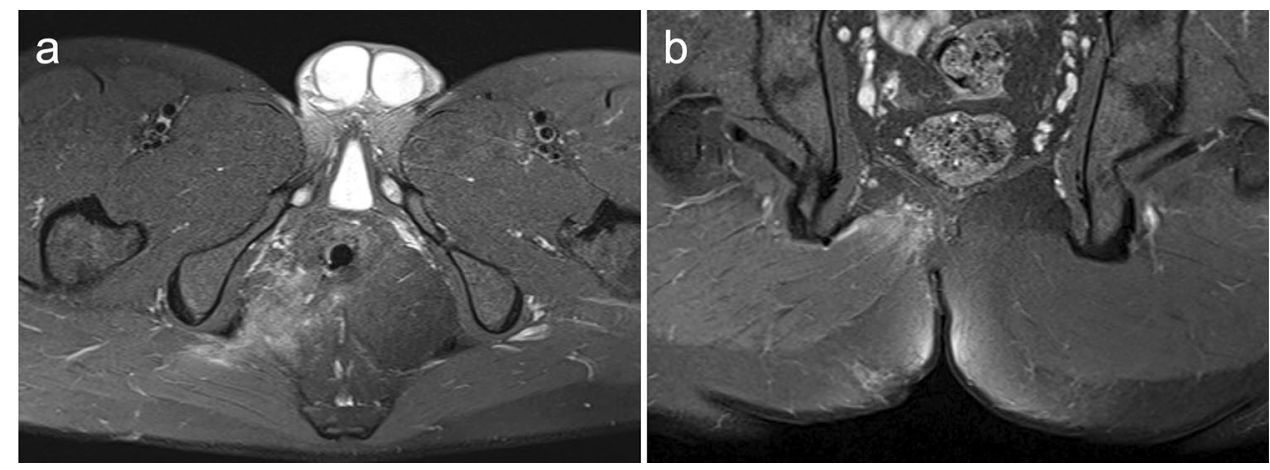

Author contributions CFX and YQD wrote the manuscript and prepared the figures (contributed equally to this work). YBY, CW and YQC drafted the design of the procedure. YBY, YBP and CW conducted the procedure. CFX, YQD and YBY provided postoperative dressing change and follow-up. All authors read and approved the final manuscript.

Funding Funded by National Natural Science Foundation of China (82174373); Xinglin scholar (tracking plan) of Shanghai University of traditional Chinese medicine; General project of Shanghai Municipal Health Commission (202040161).

\section{Declarations}

Conflict of interest All authors have nothing to disclose.

Ethical approval All procedures performed in studies involving human participants were in accordance with the ethical standards of the institutional and/or national research committee and with the 1964 Helsinki declaration and its later amendments or comparable ethical standards.

Informed consent Informed consent was obtained from the participant included in the study.
Consent for publication All authors agree to publish. Patient signed informed consent and was willing to submit the information.

Open Access This article is licensed under a Creative Commons Attribution 4.0 International License, which permits use, sharing, adaptation, distribution and reproduction in any medium or format, as long as you give appropriate credit to the original author(s) and the source, provide a link to the Creative Commons licence, and indicate if changes were made. The images or other third party material in this article are included in the article's Creative Commons licence, unless indicated otherwise in a credit line to the material. If material is not included in the article's Creative Commons licence and your intended use is not permitted by statutory regulation or exceeds the permitted use, you will need to obtain permission directly from the copyright holder. To view a copy of this licence, visit http://creativecommons.org/licenses/by/4.0/.

Publisher's Note Springer Nature remains neutral with regard to jurisdictional claims in published maps and institutional affiliations. 